\title{
Aplikasi Beberapa Fungisida Nabati Dengan Berbagai Dosis Untuk Mengendalikan Penyakit Layu Fusarium (Fusarium oxysporum) Pada Tanaman Tomat
}

\author{
(Application of Several Vegetable Fungicides With Various Doses to Control Fusarium Wilt \\ Disease (Fusarium oxysporum) on Tomato Plants)
}

\author{
Rahmi Hayati ${ }^{1}$, Tjut Chamzurni, Buni Amin ${ }^{1}$ \\ ${ }^{1}$ Program Studi Agroteknologi, Fakultas Pertanian, Universitas Syiah Kuala
}

\begin{abstract}
Abstrak. Tomat merupakan salah satu komoditas hortikultura yang mempunyai nilai ekonomi yang tinggi serta mengandung zat-zat yang bermanfaat bagi tubuh manusia seperti vitamin $\mathrm{C}$, vitamin A dan mineral. Dewasa ini produksi tomat mengalami penurunan akibat serangan penyakit layu Fusarium yang ditandai dengan pucatnya tulang-tulang daun, terutama daun-daun sebelah atas dan terkadang daun sebelah bawah. Penyakit ini disebabkan oleh patogen Fusarium oxysporum f.sp lycopersici. Pertumbuhan dan perkembangan patogen ini perlu dikendalikan secara efektif dan efisien. Salah satu upaya yang dapat dilakukan yaitu dengan menggunakan senyawa kimia yang berasal dari tumbuhan, yaitu daun sirsak, nimba dan cengkeh dengan berbagai dosis. Dimana daun tersebut mengandung senyawa yang bisa menghambat pertumbuhan dan perkembangan patogen Fusarium oxysporum. Penelitian ini menggunakan Rancangan Acak Lengkap pola Faktorial dengan 12 perlakuan. Hasil penelitian menunjukkan bahwa jenis fungisida nabati tepung daun nimba dengan dosis 50 g/polibag bisa menghambat pertumbuhan dan perkembangan Fusarium.
\end{abstract}

Kata kunci : Tomat, Fusarium oxysporum, fungisida nabati.

\begin{abstract}
Tomato is one of the horticulture commodity which has a high economic value also contain the essence of some vitamin such as vitamin $\mathrm{C}$, vitamin $\mathrm{A}$ and mineral that have a lot benefit to human being. Nowadays, the production of tomato have a significant decrease caused of the plant disease Fusarium apparently with pale steam leaves, especially up front leaves and sometimes lower leaves. This plant disease is caused by patogen Fusarium oxysporum f.sp lycopersici. The growth and development of this patogen need to be control in effective and efficient way. One of the effort that could be done is by using chemical compounds provided from plants, the soursop leaves, nimba and clove with multiple doses. The leaves contain chemical compounds that could detain the growing and developing the patogen Fusarium oxysporum. The research used complete pattern of random design factorial with 12 treatments. The result of the research showed that the type of vegetable fungicide powder with doses $50 \mathrm{~g} /$ polybag could detained the growth dan developh of Fusarium.
\end{abstract}

Keywords : Tomato, Fusarium oxysporum, vegetable fungicide

\section{PENDAHULUAN}

Tomat (Lycopersicum esculentum MILL.) merupakan salah satu komoditas hortikultura yang mempunyai nilai ekonomi yang tinggi dan masih memerlukan penanganan yang serius terutama dalam peningkatan hasil serta kualitas dari buah tomat itu sendiri (Hanindita, 2008). Badan Pusat Statistik (2013), melaporkan terjadi penurunan produksi buah tomat pada tahun 2012 sebesar $6.96 \%$. Rata-rata produksi buah tomat di Indonesia pada tahun 2011 sebesar 954.046 ton sedangkan pada tahun 2012 hanya 887.556 ton.

Layu Fusarium oxysporum merupakan salah satu penyakit penting pada tanaman tomat (Amini dan Sidovich, 2010). Borrero, et al., (2004) menyatakan, layu Fusarium adalah penyakit yang sangat penting bahkan dapat merugikan secara ekonomi. Teknik pengendalian yang paling banyak diterapkan untuk mengendalikan penyakit layu Fusarium adalah aplikasi fungisida sintetis. Akan tetapi penggunaan fungisida sintetis secara terus-menerus dapat 
menyebabkan resistensi patogen, keracunan pada manusia dan mencemari lingkungan (Hadizadeh et al., 2009).

Upaya yang dapat dilakukan untuk menekan pertumbuhan dan perkembangan Fusarium yaitu dengan menggunakan senyawa kimia yang berasal dari tumbuhan. Daun sirsak mengandung senyawa tanin, flavonoid dan fenol yang dapat bersifat sebagai anti jamur. Daun nimba juga digunakan sebagai fungisida nabati untuk mengendalikan penyakit pada tanaman, yaitu untuk mengendalikan penyakit karat daun, becak daun dan embun tepung (Lestari, 2010). Kardinan (2002), menyatakan bahwa daun cengkeh mengandung bahan aktif minyak atsiri dengan bahan utama eugenol $70-85 \%$ serta mengandung senyawa tanin, saponin dan flavonoid. Eugenol dan turunannya dapat menghambat atau menekan pertumbuhan dan perkembangan cendawan penyebab penyakit, hama, nematoda dan bakteri. Daun cengkeh juga mengandung $\mathrm{N}, \mathrm{P}, \mathrm{K}, \mathrm{Mg}, \mathrm{Fe}$ dan $\mathrm{Ca}$ dengan kadar cukup tinggi sehingga cocok dipakai sebagai pupuk organik.

Tujuan penelitian ini adalah untuk mendapatkan jenis dan dosis fungisida nabati serta interaksi keduanya yang efektif dalam mengendalikan penyakit layu Fusarium pada tanaman tomat.

\section{METODE PENELITIAN}

Penelitian ini dilaksanakan di Laboratorium Penyakit Tumbuhan Program Studi Proteksi Tanaman dan Rumah Kasa Fakultas Pertanian Universitas Syiah Kuala, yang dimulai pada bulan Mei sampai dengan Agustus 2016.

\section{MATERI DAN METODE}

Alat yang digunakan antara lain mikroskop, inkubator, timbangan analitik, autoclave, cawan petri, erlenmeyer, haemacytometer, termometer, pipet mikro, gelas ukur, tabung reaksi, gunting, blender, ayakan pasir, ayakan 60 mesh, gembor, cangkul, meteran, pisau, ajir, penggaris, kamera dan alat tulis. Bahan yang digunakan antara lain isolat jamur Fusarium oxysporum koleksi Laboratorium Mikologi Institut Pertanian Bogor (IPB), benih tomat varietas Servo F1 sebanyak 1 bungkus yang diproduksi oleh PT. East West Seed Indonesia, daun sirsak, daun nimba, daun cengkeh yang didapat di Desa Bayu Kecamatan Darul Imarah, Kabupaten Aceh Besar, media PDA, spritus, alkohol 96\%, alkohol 70\%, pupuk kompos, pupuk NPK Mutiara, aquades, plastik polietilen, tanah, babybag ukuran $10 \mathrm{~cm}$ x $12 \mathrm{~cm}$ untuk persemaian, polibag volume $10 \mathrm{~kg}$ untuk penanaman, tisu, aluminium foil, tali dan kertas label.

\section{Metode Penelitian}

Penelitian ini menggunakan Rancangan Acak Lengkap (RAL) pola faktorial 3 x 4 yang terdiri dari 2 faktor. Faktor pertama, fungisida $(F)$ terdiri dari 3 taraf yaitu : $F_{1}$ :

Daun sirsak, $F_{2}$ : Daun nimba, $F_{3}$ : Daun cengkeh. Faktor kedua, dosis (D) dengan 4 taraf yaitu : $\mathrm{D}_{0}: 0$ (Kontrol), $\mathrm{D}_{1}: 25 \mathrm{~g} /$ polibag, $\mathrm{D}_{2}: 50 \mathrm{~g} /$ polibag, $\mathrm{D} 3: 75 \mathrm{~g} /$ polibag.

\section{Perbanyakan Inokulum $F$. oxysporum f.sp lycopersici}

Isolat $F$. oxysporum f.sp lycopersici dibiakkan pada media PDA. Selanjutnya cendawan yang tumbuh diperbanyak dengan menggunakan media beras sebanyak $1 \mathrm{~kg}$ dengan cara beras dicuci bersih kemudian direndam selama 15 menit dengan air, setelah itu ditiriskan sampai beras tersebut kering dan dimasukkan ke dalam plastik tahan panas yang berukuran $1 \mathrm{~kg}$. Lalu disterilkan dengan menggunakan autoclave selama 30 menit dengan 
suhu $121^{\circ} \mathrm{C}$. Setelah itu beras didinginkan di ruangan yang steril. Kemudian Fusarium yang telah diperbanyak pada media PDA dipotong sebesar $\pm 1 \mathrm{~cm}^{2}$ lalu diinokulasi pada media beras. Media beras tersebut diinkubasi selama 30 hari dan dilakukan pengadukan setiap hari agar spora-spora yang terbentuk akan menyebar pada semua bagian beras.

\section{Pembuatan Tepung Fungisida Nabati}

Daun sirsak, nimba dan cengkeh dikeringanginkan selama 7 hari. Setelah itu dihaluskan dengan menggunakan blender dan diayak dengan menggunakan ayakan 60 mesh.

\section{Persiapan Media Tanam}

Media tanam yang digunakan dikeringanginkan di udara terbuka selama 7 hari. Tanah yang telah kering diayak dan dibersihkan dari sisa-sisa tanaman. Selanjutnya polibag volume $10 \mathrm{~kg}$ diisi tanah dan pupuk kompos dengan perbandingan 1:1. Selain itu, juga diberikan pupuk NPK sebanyak $1.5 \mathrm{~g} /$ polibag.

\section{Penanaman Bibit Tomat}

Setelah bibit tomat berumur 22 Hari Setelah Semai (bibit sudah berdaun 4-5 helai), bibit tomat dipindahkan ke polibag volume $10 \mathrm{~kg}$. Kegiatan ini dilakukan pada sore hari untuk menghindari stres tanaman tomat.

\section{Inokulasi Fusarium oxysporum f.sp lycopersici}

Inokulasi jamur Fusarium oxysporum dilakukan 1 Hari Setelah Tanam dengan cara membenamkan patogen ke dalam tanah sedalam $3 \mathrm{~cm}$ sebanyak $10 \mathrm{~g}$ substrat beras. Tanah yang sudah diinokulasikan ditutup dengan plastik transparan selama 3 hari untuk menjaga kelembaban dan merangsang pertumbuhan $F$. oxysporum (Chamzurni, et al., 2010).

\section{Aplikasi Fungisida Nabati}

Aplikasi fungisida nabati dilakukan 1 minggu setelah inokulasi $F$. oxysporum, dengan cara membenamkan tepung fungisida ke dalam tanah sedalam $3 \mathrm{~cm}$ (sesuai perlakuan).

\section{Analisa Statistik}

Selanjutnya bila hasil sidik ragam menunjukkan perbedaan yang nyata, maka akan dilanjutkan dengan Uji BNT 5\%.

\section{Pengamatan}

Adapun peubah yang diamati yaitu : masa inkubasi, persentase tanaman layu dengan rumus $\mathrm{P}=\frac{a}{b} \times 100 \%$, tinggi tanaman tomat $(\mathrm{cm})$, waktu berbunga tanaman tomat, berat buah tomat per tanaman $(\mathrm{g})$, jumlah buah per tanaman (buah) dan panjang xylem diskolorasi $(\mathrm{cm})$. 


\section{HASIL DAN PEMBAHASAN}

\section{Masa Inkubasi}

Hasil pengamatan terhadap masa inkubasi dapat dilihat pada Tabel 1.

Tabel 1. Rata-rata Masa Inkubasi Akibat Aplikasi Jenis dan Dosis Fungisida Nabati Terhadap Serangan $F$. oxysporum

\begin{tabular}{ll}
\hline \multicolumn{1}{c}{ Perlakuan } & Masa Inkubasi (HSI) \\
\hline Jenis Fungisida & \\
\hline F1 (Sirsak) & 6.72 \\
F2 (Nimba) & 6.67 \\
F3 (Cengkeh) & 6.88 \\
\hline Dosis & 6.70 \\
\hline D0 (Kontrol) & 6.89 \\
D1 (25 g/polibag) & 6.96 \\
D2 (50 g/polibag) & 6.46 \\
D3 (75 g/polibag) & \\
\hline
\end{tabular}

Masa inkubasi perlakuan jenis fungisida nabati dan dosis nilai rata-ratanya sama, yaitu 6 Hari Setelah Inokulasi (HSI). Hal ini dikarenakan jenis fungisida nabati diberikan seminggu setelah inokulasi $F$. oxysporum. Pada saat inokulasi patogen Fol terjadi curah hujan yang tinggi, sehingga kelembaban meningkat dan suhu rata-rata pada saat penelitian yaitu $25-31^{\circ} \mathrm{C}$, akibatnya masa inkubasi cepat terjadi dan menyerang semua tanaman. Hal ini sesuai dengan pendapat Clayton (1923) dalam Semangun (1989), yang menyatakan bahwa penyakit berkembang pada suhu $21-31^{\circ} \mathrm{C}$.

\section{Persentase Tanaman Layu}

Hasil Pengamatan rata-rata persentase tanaman layu dapat dilihat pada Tabel 2.

Tabel 2. Rata-rata Persentase Tanaman Layu Akibat Aplikasi Jenis dan Dosis Fungisida Nabati Terhadap Serangan F. oxysporum

\begin{tabular}{|c|c|c|c|c|c|c|}
\hline \multirow{3}{*}{ Perlakuan } & \multicolumn{6}{|c|}{ Persentase Tanaman Layu (\%) } \\
\hline & 7 & 14 & 21 & 28 & 35 & 42 \\
\hline & HSI & HSI & HSI & HSI & HSI & HSI \\
\hline \multicolumn{7}{|l|}{ Jenis Fungisida } \\
\hline F1 (Sirsak) & 86.11 & 83.34 & 77.78 & 63.89 & 63.89 & 58.33 \\
\hline F2 (Nimba) & 77.78 & 77.78 & 69.45 & 61.11 & 55.56 & 55.56 \\
\hline F3 (Cengkeh) & 80.56 & 72.23 & 69.45 & 69.45 & 66.67 & 61.11 \\
\hline $\mathrm{BNT}_{0.05}$ & - & - & - & - & - & - \\
\hline \multicolumn{7}{|l|}{ Dosis } \\
\hline D0 (Kontrol) & 66.67 & 81.48 & $81.48 \mathrm{~b}$ & $81.48 \mathrm{~b}$ & $81.48 \mathrm{~b}$ & $81.48 \mathrm{~b}$ \\
\hline D1 (25 g/polibag) & 85.19 & 74.08 & $66.67 \mathrm{a}$ & $62.97 \mathrm{a}$ & $59.26 \mathrm{a}$ & $55.56 \mathrm{a}$ \\
\hline D2 (50 g/polibag) & 88.89 & 77.78 & $74.08 \mathrm{ab}$ & $59.26 \mathrm{a}$ & $51.85 \mathrm{a}$ & $40.74 \mathrm{a}$ \\
\hline D3 (75 g/polibag) & 85.19 & 77.78 & $66.67 \mathrm{a}$ & $55.56 \mathrm{a}$ & $55.56 \mathrm{a}$ & $55.56 \mathrm{a}$ \\
\hline $\mathrm{BNT}_{0.05}$ & - & - & 10.81 & 14.30 & 15.29 & 17.09 \\
\hline
\end{tabular}


Penghambatan persentase tanaman layu akibat pemberian jenis fungisida nabati sangat terlihat pada minggu terakhir pengamatan dengan nilai rata-rata $55.56 \%$ pada perlakuan daun nimba (F2). Sedangkan persentase tanaman layu tertinggi dijumpai pada perlakuan jenis fungisida nabati daun cengkeh (F3) dengan nilai rata-rata $61.11 \%$. Untuk dosis, persentase tanaman layu tertinggi dijumpai pada perlakuan kontrol (D0) dengan nilai rata-rata $81.48 \%$. Hal ini disebabkan karena pada perlakuan kontrol (D0) tidak terdapatnya jenis dan dosis fungisida nabati yang mengandung zat penghambat pertumbuhan dan perkembangan patogen sehingga jamur Fol lebih mudah berkembang dan melakukan penetrasi di akar tanaman. Hasil penelitian Pohan (2003), melaporkan bahwa pemberian serbuk daun nimba $50 \mathrm{~g} /$ polibag dapat menghambat serangan $F$. oxysporum dengan rata-rata persentase serangan penyakit $37.50 \%$.

\section{Tinggi Tanaman Tomat $(\mathrm{cm})$}

Hasil pengamatan rata-rata tinggi tanaman tomat akibat aplikasi jenis dan dosis fungisida nabati terhadap serangan $F$. oxysporum dapat dilihat pada Tabel 3.

Tabel 3. Rata-rata Tinggi Tanaman Tomat Akibat Aplikasi Jenis dan Dosis Fungisida Nabati Terhadap Serangan F. oxysporum

\begin{tabular}{|c|c|c|c|c|c|c|}
\hline \multirow[b]{2}{*}{ Perlakuan } & \multicolumn{6}{|c|}{ Tinggi Tanaman Tomat $(\mathrm{cm})$} \\
\hline & $\begin{array}{c}7 \\
\text { HSA }\end{array}$ & $\begin{array}{c}14 \\
\mathrm{HSA}\end{array}$ & $\begin{array}{c}21 \\
\text { HSA }\end{array}$ & $\begin{array}{c}28 \\
\text { HSA }\end{array}$ & $\begin{array}{c}35 \\
\text { HSA }\end{array}$ & $\begin{array}{c}42 \\
\text { HSA }\end{array}$ \\
\hline \multicolumn{7}{|l|}{ Jenis Fungisida } \\
\hline F1 (Sirsak) & 25.99 & 31.94 & $47.40 \mathrm{a}$ & $60.47 \mathrm{a}$ & $74.44 \mathrm{~b}$ & $84.17 \mathrm{~b}$ \\
\hline F2 (Nimba) & 26.83 & 33.79 & $55.67 \mathrm{~b}$ & $71.15 \mathrm{~b}$ & $86.86 \mathrm{c}$ & $94.57 \mathrm{c}$ \\
\hline F3 (Cengkeh) & 26.89 & 32.76 & $47.72 \mathrm{a}$ & $57.72 \mathrm{a}$ & $67.18 \mathrm{a}$ & $75.40 \mathrm{a}$ \\
\hline $\mathrm{BNT}_{0.05}$ & - & - & 6.66 & 7.14 & 7.17 & 6.44 \\
\hline \multicolumn{7}{|l|}{ Dosis } \\
\hline D0 (Kontrol) & $21.86 \mathrm{a}$ & $27.26 \mathrm{a}$ & $43.22 \mathrm{a}$ & $54.29 \mathrm{a}$ & $63.11 \mathrm{a}$ & $72.05 \mathrm{a}$ \\
\hline D1 (25 g/polibag) & $30.20 \mathrm{~b}$ & $37.15 \mathrm{~b}$ & $57.07 \mathrm{~b}$ & $70.01 \mathrm{~b}$ & $83.23 \mathrm{~b}$ & $91.54 \mathrm{~b}$ \\
\hline D2 (50 g/polibag) & $27.22 \mathrm{~b}$ & $33.91 \mathrm{~b}$ & $49.93 \mathrm{ab}$ & $63.66 \mathrm{~b}$ & $78.70 \mathrm{~b}$ & $87.83 \mathrm{~b}$ \\
\hline D3 (75 g/polibag) & $26.98 \mathrm{~b}$ & $33.02 \mathrm{~b}$ & $50.83 \mathrm{ab}$ & $64.50 \mathrm{~b}$ & $79.59 \mathrm{~b}$ & $87.43 \mathrm{~b}$ \\
\hline $\mathrm{BNT}_{0.05}$ & 3.87 & 4.72 & 7.69 & 8.25 & 8.28 & 7.44 \\
\hline
\end{tabular}

Keterangan: $\quad$ Angka-angka yang diikuti huruf yang sama pada kolom yang sama berbeda tidak nyata pada taraf 5\% (Uji BNT $\left.{ }_{0.05}\right)$; HSA = Hari Setelah Aplikasi

Perlakuan menggunakan tepung daun nimba (F2) ternyata mempunyai kemampuan untuk meningkatkan tinggi tanaman secara nyata dibandingkan dengan perlakuan menggunakan jenis fungisida nabati tepung daun sirsak (F1) dan daun cengkeh (F3). Hal ini sesuai dengan pendapat Kardinan (1999), yang menyatakan bahwa daun nimba selain sebagai pestisida nabati, juga dapat digunakan sebagai pupuk organik yang berfungsi sebagai makanan bagi tanaman, sehingga dapat meningkatkan tinggi tanaman.

Tabel 3 juga menunjukkan bahwa tinggi tanaman tomat setiap minggunya yang terbaik dijumpai pada dosis fungisida nabati $25 \mathrm{~g} /$ polibag (D1). Tanaman tomat yang tidak diberi perlakuan dosis fungisida nabati pertumbuhannya terhambat. Hal ini dapat dilihat dari nilai rata-rata tinggi tanaman untuk setiap minggunya. Dimana nilai rata-rata tinggi tanaman yang terendah dijumpai pada perlakuan D0 (Kontrol).

\section{Waktu Berbunga Tanaman Tomat $(\mathbf{c m})$}

Hasil pengamatan terhadap waktu berbunga tanaman tomat dapat dilihat pada Tabel 4. 
Tabel 4. Rata-rata Waktu Berbunga Tanaman Tomat Akibat Aplikasi Jenis dan Dosis Fungisida Nabati Terhadap Serangan $F$. oxysporum

\begin{tabular}{lcc}
\hline \multicolumn{1}{c}{ Perlakuan } & Waktu Berbunga (HST) & BNT $_{0.05}$ \\
\hline Jenis Fungisida & & \\
\hline F1 (Sirsak) & 35.89 & - \\
F2 (Nimba) & 33.69 & \\
F3 (Cengkeh) & 34.75 & \\
\hline Dosis & & 3.14 \\
\hline D0 (Kontrol) & $38.85 \mathrm{~b}$ & \\
D1 (25 g/polibag) & $33.33 \mathrm{a}$ & \\
D2 (50 g/polibag) & $32.85 \mathrm{a}$ & \\
D3 (75 g/polibag) & $34.07 \mathrm{a}$ & \\
\hline
\end{tabular}

Keterangan: Angka-angka yang diikuti huruf yang sama pada pada kolom yang sama berbeda tidak nyata pada taraf $5 \%\left(\mathrm{Uji}_{\mathrm{BNT}}{ }_{0.05}\right)$; HST = Hari Setelah Tanam

Tabel 4 menunjukkan bahwa terbentuknya bunga paling cepat terdapat pada perlakuan jenis fungisida nabati daun nimba (F2) dengan nilai rata-rata 33.69 HST, dan terbentuknya bunga paling lambat terdapat pada perlakuan jenis fungisida nabati daun sirsak (F1) dengan nilai rata-rata $35.89 \mathrm{HST}$, namun ketiga jenis fungisida nabati tidak menunjukkan perbedaan yang nyata.

Dari Tabel 6 juga menunjukkan bahwa terbentuknya bunga paling cepat terdapat pada perlakuan dosis $50 \mathrm{~g} /$ polibag (D2) dengan nilai rata-rata $32.85 \mathrm{HST}$.

\section{Berat Buah Tomat per Tanaman (g)}

Hasil pengamatan terhadap berat buah tomat per tanaman dapat dilihat pada Gambar 1.

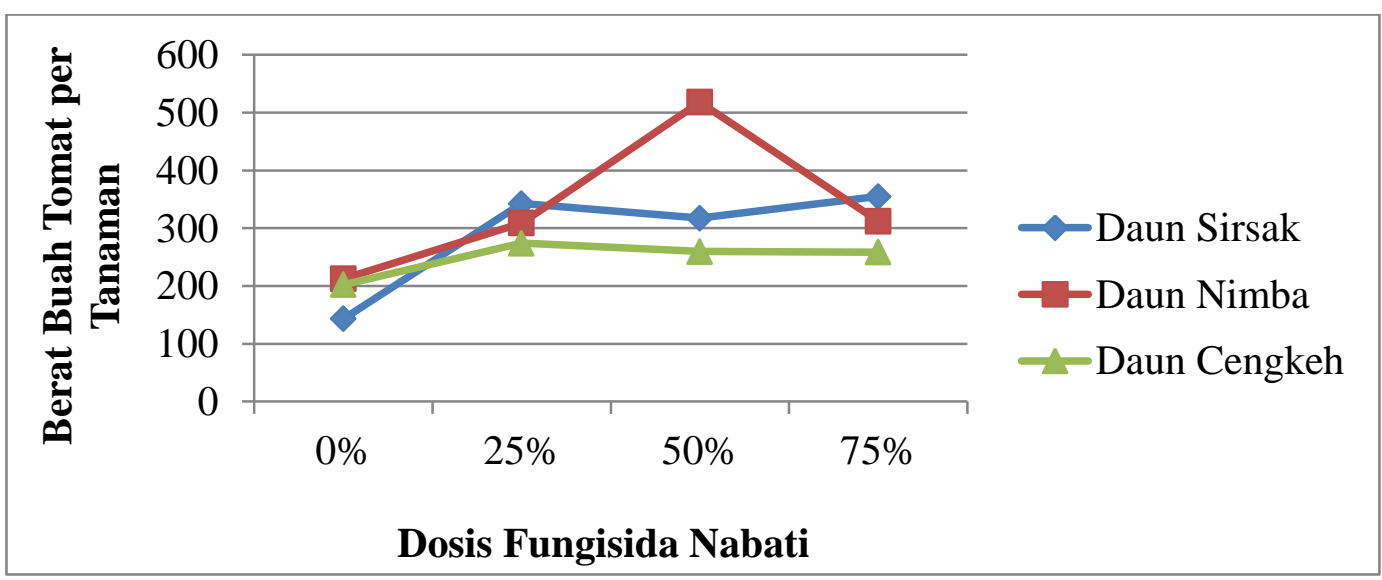

Gambar 1. Interaksi Antara Jenis dan Dosis Fungisida Nabati Terhadap Berat Buah Tomat per Tanaman

Dari Gambar 1 dapat diketahui bahwa perlakuan jenis fungisida nabati daun nimba (F2) dengan dosis $50 \mathrm{~g} /$ polibag (D2) mampu meningkatkan berat buah tanaman tomat dan memberikan nilai tertinggi yaitu $517.96 \mathrm{~g}$ dibandingkan dengan perlakuan lainnya. Produksi tanaman erat kaitannya dengan intensitas serangan, semakin tinggi intensitas serangan maka produksi akan semakin rendah dan sebaliknya semakin rendah intensitas serangan maka semakin tinggi produksinya. Susanna et al., (2010) melaporkan, rendahnya produksi tanaman tomat disebabkan oleh patogen Fol yang berkolonisasi di bagian xylem yang mengakibatkan terganggunya proses translokasi unsur hara, air dan garam-garam mineral ke tanaman, 
akibatnya patogen dengan mudah menyerang tanaman tomat sehingga dapat menurunkan hasil.

\section{Jumlah Buah Tomat per Tanaman (buah)}

Hasil pengamatan terhadap jumlah buah tomat per tanaman dapat dilihat pada Gambar 2.

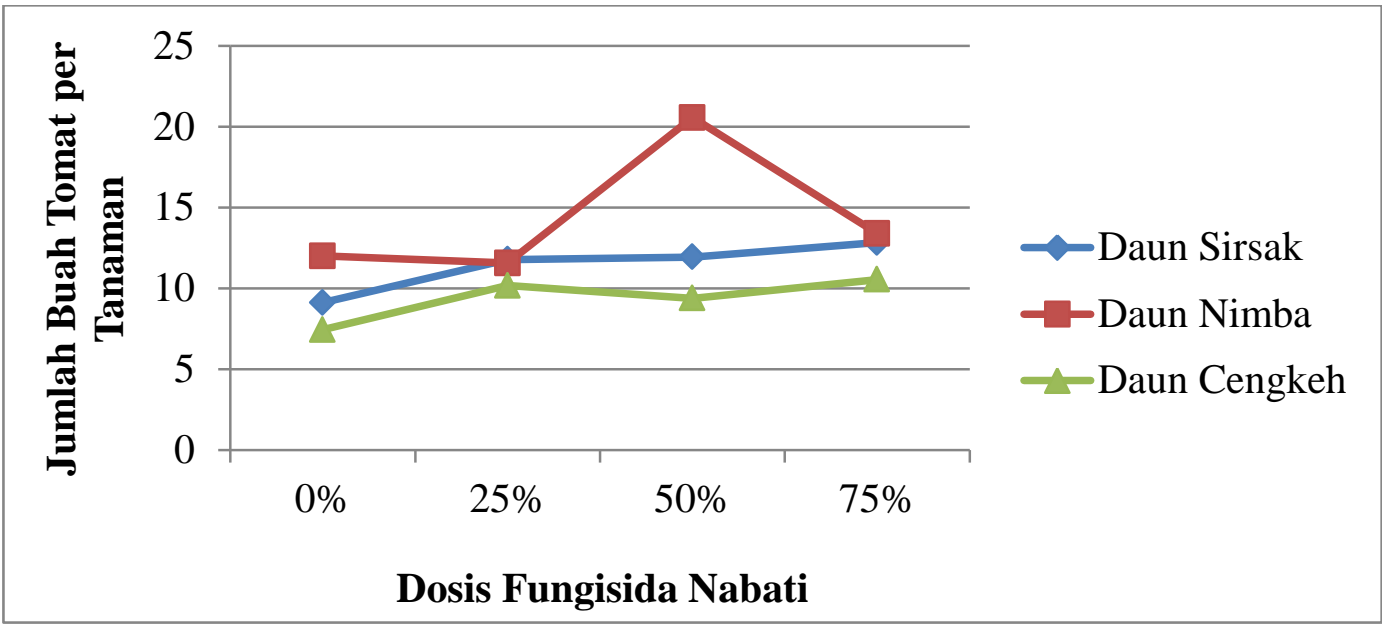

Gambar 2. Interaksi Antara Jenis dan Dosis Fungisida Nabati Terhadap Jumlah Buah Tomat per Tanaman

Gambar 2 menunjukkan bahwa jumlah buah tomat pada perlakuan jenis fungisida nabati daun nimba yang terbanyak dijumpai pada dosis $50 \mathrm{~g} /$ polibag dengan nilai rata-rata 20.56 buah. Hal ini dikarenakan senyawa yang dikandung daun nimba seperti azadirachtin, salanin dan nimbin bisa menghambat pertumbuhan dan perkembangan patogen Fusarium oxysporum. Senada dengan hal itu, Novizan (2002), menyatakan bahwa daun nimba mengandung azadirachtin yang mampu menghambat perkecambahan spora dan konidium jamur. Salanin berperan sebagai penurun nafsu makan yang mengakibatkan daya rusak serangga menurun. Nimbin berperan sebagai antimikroorganisme seperti antivirus, bakterisida dan fungisida yang digunakan untuk mengendalikan penyakit tanaman (Ruskin, 1993).

Jumlah buah terendah dijumpai pada perlakuan kontrol. Hal ini disebabkan karena pada perlakuan kontrol tidak terdapat jenis fungisida nabati yang mengandung zat penghambat pertumbuhan dan perkembangan patogen.

Tanaman yang terserang Fol masih dapat tumbuh, akan tetapi pertumbuhan dan perkembangan tanamannya terganggu. Dampak yang diperlihatkan adalah produksinya yang rendah dan buahnya pun kecil-kecil.

\section{Panjang Xylem Diskolorasi Tanaman Tomat (cm)}

Hasil pengamatan terhadap panjang xylem diskolorasi tanaman tomat dapat dilihat pada Gambar 3. 


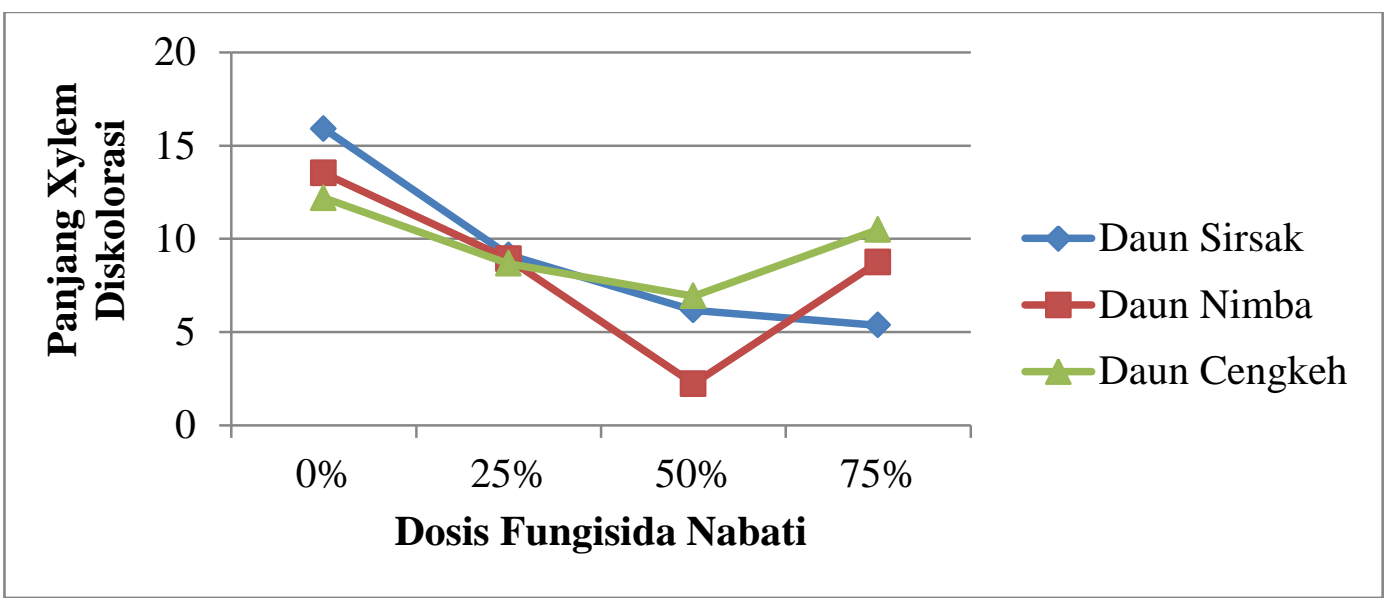

Gambar 3. Interaksi Antara Jenis dan Dosis Fungisida Nabati Terhadap Panjang Xylem Diskolorasi Tanaman Tomat

Gambar 3 terlihat bahwa xylem diskolorasi yang terpanjang terdapat pada perlakuan kontrol (D0). Sedangkan xylem diskolorasi terpendek terdapat pada perlakuan jenis fungisida nabati daun nimba (F2) dengan dosis 50 g/polibag. Panjangnya xylem diskolorasi pada perlakuan kontrol disebabkan tidak terdapatnya jenis fungisida nabati yang bisa menghambat infeksi Fol. Oleh sebab itu patogen dengan mudah melakukan penetrasi ke dalam jaringan yang terdapat pada akar dan berkembang pada jaringan korteks, setelah itu masuk ke jaringan xylem serta berkolonisasi di dalamnya dan mengeluarkan toksin yang berupa likomarasmin dan asam fusarik sehingga menyebabkan perubahan warna jaringan tersebut menjadi cokelat (Susanna et al., 2010).

Berdasarkan hasil penelitian dapat diketahui bahwa jenis fungisida nabati daun nimba dengan dosis $50 \mathrm{~g} /$ polibag mampu menghambat pertumbuhan dan perkembangan patogen Fol sehingga xylem diskolorasinya pendek, dengan nilai rata-rata $2.23 \mathrm{~cm}$.

\section{KESIMPULAN DAN SARAN}

Pengendalian penyakit layu Fusarium pada tanaman tomat yang terbaik terdapat pada perlakuan jenis fungisida nabati daun nimba dengan dosis $50 \mathrm{~g} /$ polibag dapat menghambat pertumbuhan dan perkembangan Fusarium dengan nilai rata-rata $33.33 \%$.

\section{DAFTAR PUSTAKA}

Amini, J dan D.F. Sidovich. 2010. The effects of fungicides on Fusarium oxysporum f.sp. lycopersici associated with Fusarium wilt of tomato. Journal of plant protection research. 50 (2).

Badan Pusat Statistik. 2013. Produksi sayuran di Indonesia tahun 19972012.http://www.bps.go.id/tab_sub/view.php?kat=3\&tabel=1\&daftar=1\&id_subyek=5 $5 \&$ notab=70/Produksi Sayuran di Indonesia, 1997-2012. [Diakses tanggal 06 Desember 2015]. 
Borrero, C., M.I. Trillas, J. Ordovás, J.C. Tello dan M. Avilés. 2004. Predictive factors for the suppression of Fusarium wilt of tomato in plant growth medium. Phytopathology 94 (10):1094-1101.

Chamzurni, T., M.A. Ulim dan E. Dianur. 2010. Uji ketahanan beberapa varietas tomat terhadap penyakit layu Fusarium (Fusarium oxysporum f.sp lycopersici). J. Agrista 14 (2).

Hadizadeh, I., B. Peivastegan dan H. Hamzehzarghani. 2009. Antifungal activity of essential oils from some medicinal plants of Iran against Alternaria alternate. American Journal of Applied Sciences 6 (5): 857-861.

Hanindita, N. 2008. Analisis ekspor tomat segar Indonesia. Ringkasan Eksekutif Program Pascasarjana Manajemen Bisnis Institut Pertanian Bogor.

Kardinan, A. 1999. Nimba (Azadirachta indica A. Juss) pestisida yang sangat menjanjikan. Pemanfaatan pestisida nabati. Perkembangan Teknologi Tanaman Rempah dan Obat 9 (2): 34-40.

Kardinan, A. 2002. Pestisida nabati, ramuan dan aplikasi. Penebar Swadaya. Jakarta.

Lestari. 2010. Pengendalian hama dan penyakit dengan pestisida organik. Bogor. http://saung tani.blog/ [Diakses tanggal 24 November 2015).

Novizan. 2002. Membuat dan memanfaatkan pestisida ramah lingkungan. Agromedia Pustaka, Jakarta.

Pohan, M.N. 2003. Uji efektivitas serbuk cengkeh (Syzygium aromaticum L.) dan nimba (Azadirachta indica A. Juss) terhadap perkembangan penyakit layu (Fusarium oxysporum f.sp capsici) pada tanaman cabai (Capsicum annum L.). Skripsi. Universitas Sumatera Utara. Medan.

Ruskin. 1993. Pestisida nabati: ramuan dan aplikasi. Penebar Swadaya. Jakarta.

Semangun, H. 1989. Penyakit-penyakit tanaman hortikultura di Indonesia. Gadjah Mada University Press. Yogyakarta.

Susanna, T. Chamzurni dan A. Pratama. 2010. Dosis dan frekuensi kascing untuk pengendalian penyakit layu Fusarium pada tanaman tomat. J. Floratek 5: 152-163. 